\title{
Relação entre as características e o uso das informações de levantamentos de solos de diferentes escalas
}

\author{
Relationship between characteristics and use of different scales soil surveys information
}

Ricardo Simão Diniz Dalmolin ${ }^{1}$ Egon Klamt ${ }^{2}$ Fabrício de Araújo Pedron ${ }^{3}$ Antônio Carlos de Azevedo ${ }^{4}$

RESUMO

\begin{abstract}
A relação entre as características e a utilização das informações do mapa do levantamento de reconhecimento de solos do estado do Rio Grande do Sul na escala de 1:750.000 e dos mapas semidetalhados dos municípios de São João do Polêsine - RS (SJP), na escala de 1:20.000, e São Pedro do Sul - RS (SPS), na escala 1:50.000, foi estudada. Para este fim, comparou-se a área total em hectares e a percentagem de área do município ocupada por cada classe de solo delineada nos diferentes mapas. Foram verificadas grandes diferenças quanto ao número, tipo $e$ distribuição das classes de solos delineadas. A ampliação de mapas de pequena escala não permite identificar e delinear solos que ocorrem na área estudada e que não foram delineadas por problemas de escala. Para planejamento de uso dos solos de propriedades rurais, microbacias $e$ municipios, levantamentos detalhados e semidetalhados devem ser elaborados.
\end{abstract}

Palavras-chave: levantamento de solos, mapas de solo, classes de solos, cartografia.

\section{ABSTRACT}

The relationship between the characteristics and use of information of the reconnaissance soil survey map of the state of Rio Grande do Sul in the scale of 1:750.000 and the semidetailed maps of the São João do Polêsine county (SJP), in the scale of 1:20.000, and São Pedro do Sul county $(S P S)$, in the scale 1:50.000 was studied. For this purpose the total area, in hectares, was compared, and the percentage of area of the counties occupied by the different soil classes, delineated in different maps. Differences were verified concerning the main classes of soils delineated in the maps and also in the percentage of distribution of the area occupied by the classes in these maps. For this reason, the enlargement of soil maps of small scale doesn't permit to identify and to delineate soils that occur in the studied area, and which were not mapped due to the limitations in scale. For planning use of soils in watersheds, counties and farm areas, detailed and semidetailed surveys should be elaborated.

Key words: soil survey, soil maps, soil classes, cartography.

\section{INTRODUÇÃO}

Os levantamentos de solos constituem um inventário das características morfológicas, físicas, químicas e mineralógicas dos solos, bem como apresentam a classificação taxonômica e interpretativa e a distribuição geográfica dos mesmos na área abrangida pelo estudo. A distribuição geográfica dos solos é representada em mapas, enquanto as demais informações são descritas nos relatórios dos levantamentos.

O nível de detalhe das informações contidas nos levantamentos de solos depende da escala e do objetivo para o qual foram confeccionados. Por convenção cartográfica, a menor dimensão legível em mapas é a área de $0,4 \mathrm{~cm}^{2}$, que representa a área mínima mapeável (AMM) no terreno (DENT \& YOUNG, 1981). Esta AMM no terreno depende da escala em que o mapa de solos é confeccionado.

No mapa de solos do levantamento dos Recursos Naturais realizado pelo Projeto RADAMBRASIL(IBGE, 1986) na escala de 1:1.000.000, a AMM é de 4.000 ha, enquanto que, no Levantamento de Reconhecimento de Solos do Estado do Rio Grande do Sul (BRASIL, 1973), na escala de 1:750.000, esta é de 2250ha. Já no mapa de solos de São João do Polêsine

\footnotetext{
${ }^{1}$ Engenheiro Agrônomo, Doutor, Professor do Departamento de Solos, Universidade Federal de Santa Maria (UFSM), 97105-900, Santa Maria, RS. E-mail: dalmolin@ccr.ufsm.br, Autor para correspondência.

${ }^{2}$ Engenheiro Agrônomo, PhD, Professor aposentado do Departamento de Solos, Universidade Federal do Rio Grande do Sul.

${ }^{3}$ Engenheiro Agrônomo, Aluno de Mestrado do Programa de Pós-graduação em Ciência do Solo, UFSM.

${ }^{4}$ Engenheiro Agrônomo, PhD, Professor do Departamento de Solos, UFSM.
} 
(SJP) (KLAMT et al., 1997), na escala de 1:20.000, a AMM é de 1,6ha, enquanto que no mapa de solos de São Pedro do Sul (SPS) (KLAMT et al., 2000) na escala 1:50.000 a AMM é de 10ha. Isto significa que solos que ocupam áreas inferiores a AMM não podem ser representados no mapa. Para contornar este problema utilizam-se artifícios, tais como a criação de delineamentos representados por unidades combinadas que, no mapa, são apresentadas como associações, complexos ou grupos indiferenciados de solos. Quando em unidades de mapeamento simples ou combinadas, ocorrem classes de solo que representam menos do que $20 \%$ da área total da unidade de mapeamento, estas são referenciadas como inclusões (EMBRAPA, 1995).

É importante considerar que mapas de solo em escala pequena, como 1:750.000 ou 1:1.000.000, não são adequadas para planejamento de uso e manejo de solos de municípios, bacias hidrográficas ou propriedades rurais. Estes mapas podem ser usados apenas para planejamento de uso de solos em grandes áreas, como estudos para zoneamento pedoclimático, seleção de áreas para projetos de colonização, construção de rodovias e ferrovias, localização de estações experimentais e de disponibilidade de materiais para construção, entre outras (EMBRAPA, 1995). Para planejamento de uso de solos em pequenas áreas, como municípios, bacias hidrográficas, projetos de assentamento, propriedades rurais, são necessários mapas na escala de 1:50.000 ou maiores, existentes no estado do Rio Grande do Sul apenas em áreas restritas, como por exemplo, os municípios de São João do Polêsine, São Pedro do Sul, Silveira Martins e Ibirubá. A tendência de ampliar áreas de municípios ou mesmo de propriedades rurais a partir de mapas de pequena escala, não é adequada, visto que informações mais detalhadas sobre a ocorrência e distribuição de solos não são obtidas por este procedimento. O presente trabalho tem como objetivo efetuar estudo comparativo das informações dos mapas ampliados de solo dos Municípios de SJP e SPS, extraídos do levantamento de reconhecimento de solos do estado do RS, na escala de 1:750.000 e dos mapas confeccionados para estes municípios na escala de 1:20.000 e 1:50.000, respectivamente.

\section{MATERIAL E MÉTODOS}

Numa primeira etapa, ampliou-se para a escala 1:20.000 e 1:50.000, respectivamente, a área correspondente aos municípios de SJP e SPS, tendo por base o mapa de solos contido no levantamento de reconhecimento de solos do Rio Grande do Sul
(BRASIL, 1973) na escala de 1:750.000. A classificação dos solos apresentada no mapa do município de SJP (KLAMT et al., 1997) foi atualizada de acordo com o Sistema Brasileiro de Classificação de Solos (EMBRAPA, 1999). Para digitalização das unidades de mapeamento de ambos os mapas (SJP e SPS), utilizou-se o aplicativo Idrisi 32-release 2 (EASTMAN, 2001). O mapa de solos de SPS (KLAMT et al., 2001), na escala 1:50.000, assim como o mapa de reconhecimento de solos do Rio Grande do Sul (BRASIL, 1973), na escala de 1:750.000, foram escanerizados e importados para o aplicativo Idrisi, onde os arquivos foram georeferenciados com pontos de controle conhecidos encontrados na carta topográfica da Diretoria do Serviço Geográfico do Exército (DSG), folha de São Pedro do Sul, na escala 1:50.000. Na seqüência, ambos os mapas tiveram suas unidades de solos digitalizadas, gerando arquivos vetoriais, os quais foram rasterizados utilizando-se rotinas do aplicativo Idrisi. A partir dos mapas rasterizados foram gerados arquivos com as áreas referentes às classes de solos ocorrentes em cada mapa, e sequiencialmente, foi realizada a sobreposição dos mapas, buscando identificar as diferenças e coincidências entre estes, em relação aos solos. O mesmo procedimento foi efetuado para o registro e sobreposição do mapa de solos de SJP (KLAMT et al., 1997), na escala 1:20.000, com o mapa de reconhecimento de solos do Rio Grande do Sul, na escala 1:750.000. Os pontos de controle para o registro do mapa de solos de SJP foram retirados de cartas topográficas das folhas de Camobi e de Faxinal do Soturno, na escala 1:50.000.

As unidades de mapeamento de ambos os mapas, em nível semidetalhado, foram quantificadas em termos de área de abrangência e de percentagem de ocorrência no município, para facilitar o estudo comparativo proposto para a determinação das unidades existentes em cada mapa de solo. As figuras que representam os mapas (Figura 1 e Figura 2) tem por finalidade apenas mostrar a grande diferença na área e distribuição dos solos na comparação das diferentes escalas. A quantificação destas áreas está apresentada nas tabelas 1 e 2 .

\section{RESULTADOS E DISCUSSÃO}

Na figura 1, é mostrado o mapa de solos do município de SJP obtido por ampliação do mapa de reconhecimento, juntamente com o mapa semidetalhado de solos. No mapa de solos ampliado (Figura 1B), pode-se observar a ocorrência de três diferentes classes taxonômicas e uma associação de 


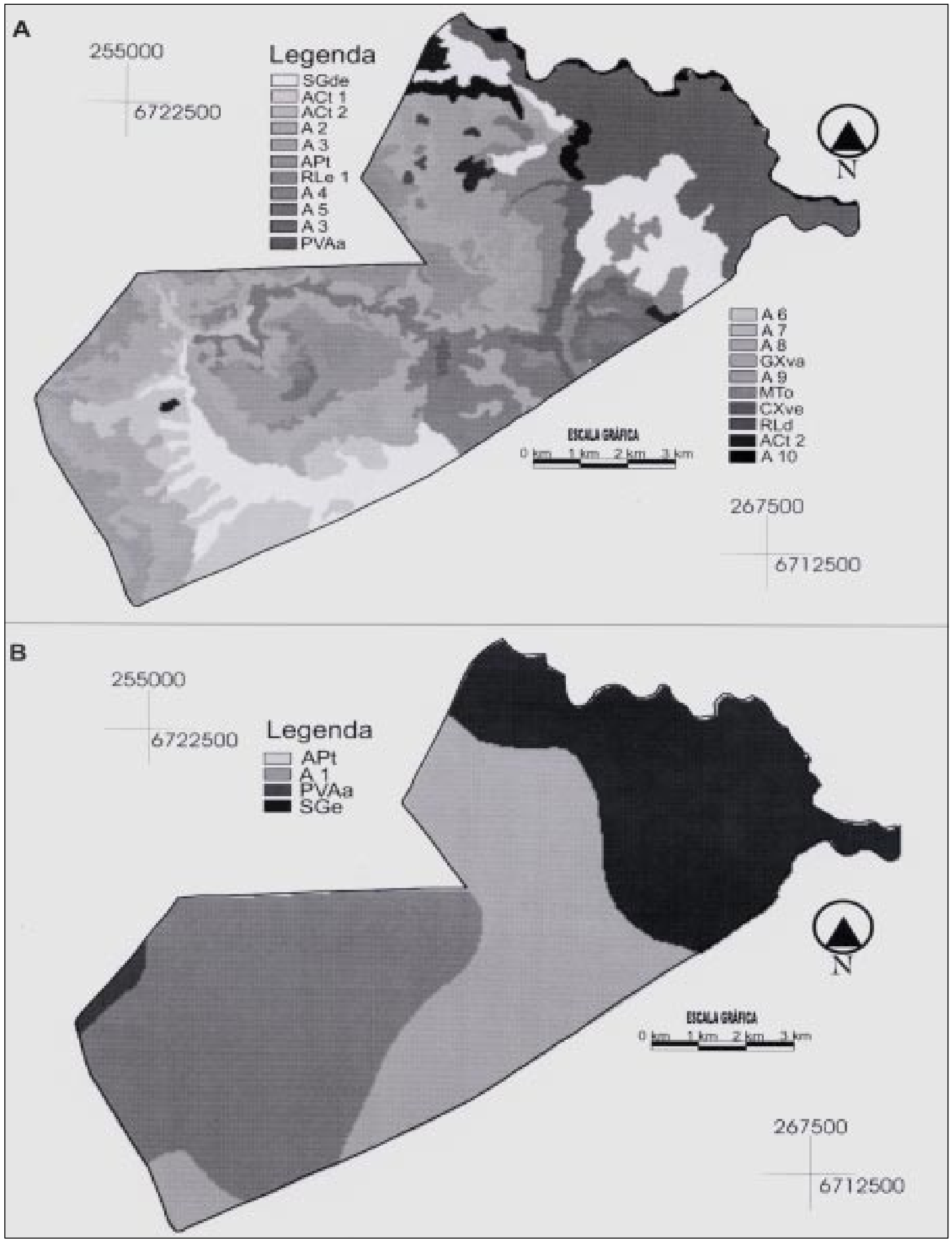

Figura 1 - Mapa de solos do município de SJP, publicado na escala 1:20.000 (A) e ampliado do mapa de reconhecimento na escala $1: 750.000(\mathrm{~B})$ 


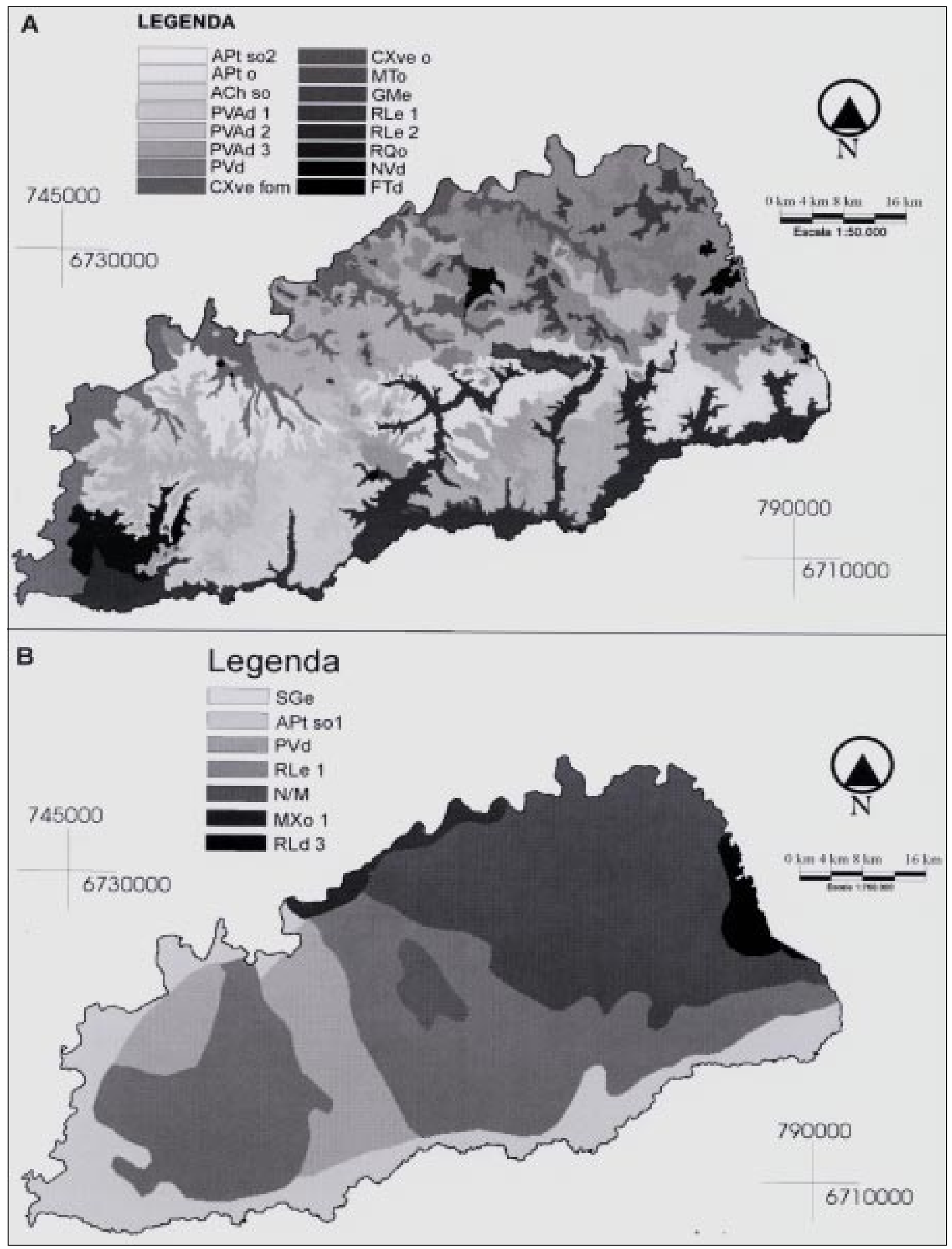

Figura 2 - Mapa de solos do município de SPS, publicado na escala 1:50.000 (A) e ampliado do mapa de reconhecimento na escala $1: 750.000(\mathrm{~B})$.

Ciência Rural, v.34, n.5, set-out, 2004. 
Tabela 1 - Comparação dos tipos de solos encontrados nos diferentes levantamentos de solos do município de SJP.

\begin{tabular}{|c|c|c|c|}
\hline \multirow[b]{2}{*}{ Solos } & \multirow[b]{2}{*}{ Símbolo } & \multicolumn{2}{|c|}{ Áreas (hectares) } \\
\hline & & $\begin{array}{c}\text { Mapa de solos } \\
\text { ampliado de } \\
1 / 750.000^{1}\end{array}$ & $\begin{array}{l}\text { Mapa de } \\
\text { solos } \\
1 / 20.000^{2}\end{array}$ \\
\hline Planossolo Hidromórfico eutrófico arênico textura média relevo plano & SGe & 2.540 & 0 \\
\hline $\begin{array}{l}\text { Planossolo Hidromórfico distrófico - eutrófico arênico A proeminente - moderado textura } \\
\text { argilosa relevo suave ondulado }\end{array}$ & SGde & 0 & 1.285 \\
\hline Alissolo Hipocrômico argilúvico típico textura média relevo suave ondulado & APt & 2.927 & 25 \\
\hline Alissolo Crômico argilúvico abrúptico A moderado textura argilosa relevo suave ondulado & ACt 1 & 0 & 537 \\
\hline $\begin{array}{l}\text { Alissolo Crômico argilúvico abrúptico A moderado textura argilosa relevo ondulado a forte } \\
\text { ondulado }\end{array}$ & ACt 2 & 0 & 311 \\
\hline Neossolo Litólico eutrófico típico A moderado textura média relevo montanhoso & RLe & 0 & 864 \\
\hline Neossolo Litólico distrófico típico A proeminente textura média relevo ondulado & RLd & 0 & 31 \\
\hline $\begin{array}{l}\text { Argissolo Vermelho - Amarelo alumínico alissólico A moderado textura argilosa relevo suave } \\
\text { ondulado }\end{array}$ & PVAa & 76 & 123 \\
\hline Gleissolo Háplico Ta alumínico típico A moderado textura média relevo plano & GXva & 0 & 1.385 \\
\hline Chernossolo Argilúvico órtico típico textura média relevo forte ondulado & MTo & 0 & 14 \\
\hline $\begin{array}{l}\text { Cambissolo Háplico Ta eutrófico típico A chernozêmico textura muito argilosa relevo forte } \\
\text { ondulado }\end{array}$ & CXve & 0 & 4 \\
\hline Associação Chernossolo + Neossolo & A 1 & 3.432 & 0 \\
\hline Associação ACt + CXve + RLe & A 2 & 0 & 1.670 \\
\hline Associação CXve + ACt & A 3 & 0 & 1.500 \\
\hline Associação PVAa + ACt & A 4 & 0 & 166 \\
\hline Associação APt + RLe & A 5 & 0 & 138 \\
\hline Associação ACt + APt & A 6 & 0 & 581 \\
\hline Associação ACt + RLd & A 7 & 0 & 167 \\
\hline Associação CXve + RLe & A 8 & 0 & 89 \\
\hline Associação APt + SGed & A 9 & 0 & 20 \\
\hline Associação Cambissolo + Solos Aluviais não caracterizados & A 10 & 0 & 61 \\
\hline
\end{tabular}

${ }^{1}$ Mapa de solos do Rio Grande do Sul, escala 1:750.000 (BRASIL, 1973)

${ }^{2}$ Mapa de solos do Município de São João do Polêsine, escala 1:20.000 (KLAMT et al., 1997)

solos: Argissolo Vermelho - Amarelo alumínico (PVAa), ocupando $0,84 \%$ da área do município; Alissolo Hipocrômico argilúvico (APt), ocupando 32,61\%; Planossolo Hidromórfico eutrófico (SGe) que ocupam 28,30\% e Associação Chernossolo argilúvico Neossolo Litólico (A1) com 38,24\% de ocorrência. No mapa do Levantamento semidetalhado de solos do município de SJP publicado na escala de 1:20.000 (Figura 1A), observa-se dez diferentes classes e nove associações de solos, os quais são apresentados na Tabela 1. Verifica-se que, no mapa ampliado deste município, 3.432ha são ocupados pela associação Chernossolo - Neossolo (A1), os quais apresentam várias restrições ao uso agrícola (STRECK et al., 2002), sendo o Neossolo considerado inapto para a agricultura segundo o sistema de aptidão agrícola das terras de RAMALHO FILHO \& BEEK (1995). No mapa de solos semidetalhado de SJP, esta área é ocupada por 8.950ha de Neossolos (RLe e RLd), 144ha de Chernossolo (MTo) e nos restantes 2.522ha são encontradas diversas classes e outras associações de solos como: Planossolos, Alissolos, Argissolos, Associações de Alissolo - Cambissolo (A3), Alissolo - Argissolo (A4), Alissolo - Neossolo (A7) e Alissolo - Cambissolo - Neossolo (A2). Desta forma, a utilização do mapa ampliado de solos de SJP para planejamento municipal poderia subestimar terras com melhor aptidão agrícola, excluindo parte do município de projetos agropecuários. Comparando os mapas de solos de SJP, verifica-se que, dos 2.540ha de Planossolos Hidromórficos (SGe) encontrados no mapa ampliado do mapa de reconhecimento, 1.287ha são, segundo o mapa semidetalhado, Gleissolos Háplico (GXva). Estes solos apresentam propriedades morfológicas e físicas distintas (EMBRAPA, 1999), o que pode implicar em aptidão agrícola e manejo diferenciado.

No que se refere à classe dos Argissolos, Alissolos e as associações entre estas duas classes, contidas no levantamento semidetalhado do município 
Tabela 2 - Comparação dos tipos de solos encontrados nos diferentes levantamentos de solos de SPS.

\begin{tabular}{|c|c|c|c|}
\hline \multirow[b]{2}{*}{ Solos } & \multirow[b]{2}{*}{ Símbolo } & \multicolumn{2}{|c|}{ Áreas (hectares) } \\
\hline & & $\begin{array}{c}\text { Mapa de } \\
\text { solos } \\
\text { ampliado } \\
\text { de } \\
1 / 750.000^{1}\end{array}$ & $\begin{array}{c}\text { Mapa de } \\
\text { solos } \\
1 / 50.000^{2}\end{array}$ \\
\hline Planossolo Hidromórfico eutrófico arênico textura média relevo plano & $\mathrm{SGe}$ & 14.467 & 0 \\
\hline $\begin{array}{l}\text { Neossolo Litólico eutrófico típico A moderado textura média e argilosa relevo suave ondulado a } \\
\text { ondulado }\end{array}$ & RLe 1 & 1.435 & 3.970 \\
\hline Neossolo Litólico eutrófico típico A moderado textura argilosa relevo forte ondulado e montanhoso & RLe 2 & 0 & 403 \\
\hline Neossolo Litólico distrófico típico textura média relevo forte ondulado & RLd & 1.478 & 0 \\
\hline Chernossolo Háplico órtico típico textura argilosa fase relevo plano & MXo & 1.471 & 0 \\
\hline Associação Neossolo + Chernossolo & $\mathrm{N} / \mathrm{M}$ & 25.327 & 0 \\
\hline Alissolo Hipocrômico argilúvico típico textura média relevo suave ondulado & APt so 1 & 9.516 & 0 \\
\hline $\begin{array}{l}\text { Alissolo Hipocrômico argilúvico abrupto A proeminente textura arenosa/média relevo suave } \\
\text { ondulado }\end{array}$ & APt so 2 & 0 & 8.343 \\
\hline $\begin{array}{l}\text { Alissolo Hipocrômico argilúvico abrupto A proeminente textura arenosa/média relevo suave } \\
\text { ondulado a ondulado }\end{array}$ & APt o & 0 & 2.572 \\
\hline $\begin{array}{l}\text { Alissolo Crômico húmico câmbico A proeminente textura arenosa/média relevo suave ondulado a } \\
\text { ondulado }\end{array}$ & ACh so & 0 & 11.869 \\
\hline Argissolo Vermelho distrófico arênico textura média relevo suave ondulado a ondulado & PVd & 31.874 & 2.871 \\
\hline $\begin{array}{l}\text { Argissolo Vermelho-Amarelo distrófico espessarênico A moderado textura arenosa/média relevo } \\
\text { suave ondulado }\end{array}$ & PVAd 1 & 0 & 1.788 \\
\hline $\begin{array}{l}\text { Argissolo Vermelho-Amarelo distrófico arênico A moderado textura arenosa/média relevo suave } \\
\text { ondulado }\end{array}$ & PVAd 2 & 0 & 3.888 \\
\hline $\begin{array}{l}\text { Argissolo Vermelho-Amarelo distrófico abrupto A moderado textura arenosa/argilosa relevo suave } \\
\text { ondulado a ondulado }\end{array}$ & PVAd 3 & 0 & 11.218 \\
\hline $\begin{array}{l}\text { Cambissolo Háplico Ta eutrófico léptico A moderado textura argilosa relevo forte ondulado e } \\
\text { montanhoso }\end{array}$ & CXve fom & 0 & 13.579 \\
\hline $\begin{array}{l}\text { Cambissolo Háplico Ta eutrófico léptico A moderado textura argilosa relevo forte ondulado a } \\
\text { ondulado }\end{array}$ & CXve o & 0 & 29.350 \\
\hline Gleissolo Melânico eutrófico chernossólico textura argilosa relevo plano & GMe & 0 & 8.880 \\
\hline $\begin{array}{l}\text { Associação Neossolo Quartzarênico órtico + Gleissolo Melânico eutrófico, ambos típicos A } \\
\text { moderado relevo plano }\end{array}$ & RQo & 0 & 10.932 \\
\hline $\begin{array}{l}\text { Nitossolo Vermelho distrófico argiloso A proeminente textura argilosa relevo suave ondulado a } \\
\text { ondulado }\end{array}$ & $\mathrm{NVd}$ & 0 & 654 \\
\hline Plintossolo Argilúvico distrófico arênico A moderado & FTd & 0 & 1.952 \\
\hline Área inundada & & 0 & 254 \\
\hline
\end{tabular}

${ }^{1}$ Mapa de solos do Rio Grande do Sul, escala 1:750.000 (BRASIL, 1973)

${ }^{2}$ Mapa de solos do Município de São Pedro do Sul, escala 1:50.000 (KLAMT et al., 2001)

de SJP, as quais se assemelham em termos de características e vocação de uso agrícola, observa-se um total de 1.713 ha ou $19,16 \%$ destas classes no município, valor este, muito inferior aos $2.927 \mathrm{ha} \mathrm{ou}$ $32,61 \%$ da área obtida do mapa ampliado do levantamento de reconhecimento de solos do RS (BRASIL, 1973).

Para fins de planejamento de uso dos solos de SJP, o maior problema refere-se à grande variabilidade de solos existentes nesta área, a qual não é representada nos levantamentos de reconhecimento, por limitação de escala. SALEHI et al. (2003) também aponta a existência de variabilidade espacial de solos em levantamentos de diferentes escalas, dificultando a otimização de uso destas terras. Em SJP, a superestimação de Planossolos Hidromórficos no mapa ampliado a partir do levantamento de reconhecimento, poderia provocar falhas em projetos de incentivo ao desenvolvimento da orizicultura, a qual é extremamente importante na região. Da mesma forma, a superestimação de áreas com Neossolos e Chernossolos poderia não somente 
prejudicar a exploração agrícola de milhares de hectares com esta aptidão, mas também dificultar o planejamento de áreas de preservação permanente de acordo com a legislação federal e estadual.

Quanto à SPS (Figura 2), o mapa ampliado a partir do mapa de reconhecimento de solos (BRASIL, 1973) apresenta seis classes de solos e uma associação (Figura 2B), enquanto o mapa de solos semidetalhado (KLAMT et al., 2001) apresenta 14 classes e uma associação de solos (Figura 2A). No mapa ampliado, 31.874 ha ou $37,25 \%$ da área é ocupada por Argissolo Vermelho Distrófico arênico textura média relevo suave-ondulado a ondulado (PVd) (Tabela 2), porém, tal classe aparece no mapa semidetalhado com apenas 2.871 ha ou 3,36\% da área do município. Mesmo somando os demais Argissolos existentes, a área ocupada ainda seria inferior aquela apresentada no mapa de reconhecimento ampliado. Contudo, é importante saber que a soma dos diferentes Argissolos que ocorrem no mapa semidetalhado não é aconselhada devido às variações apresentadas por estes solos nos diferentes níveis categóricos, principalmente ao nível de fase, como o relevo. Estas variações vão implicar aptidão de uso e de manejo diferenciados.

No mapa de reconhecimento ampliado do município de SPS também ocorrem problemas com os Planossolos Hidromórficos (SGe), os quais possuem uma área de 14.467ha, enquanto é inexistente no mapa semidetalhado. Neste mapa, as áreas de Planossolos são ocupadas por Alissolos Crômicos e Hipocrômicos (2.396ha), Argissolos Vermelhos e Vermelhos Amarelos (1.277ha), Gleissolos Melânicos (3.807ha), Associação Neossolo Quartzarênico - Gleissolo Melânico (5.550ha), Neossolo Litólico (990ha), Plintossolos Argilúvicos (1.092ha) e Cambissolos Háplicos (246ha). Da mesma forma, estes solos possuem características completamente distintas e necessitam de manejo totalmente diferente dos Planossolos descritos no mapa de reconhecimento ampliado.

Outra divergência encontrada entre os mapas de solos do município de SPS está relacionada com a associação Neossolo Litólico - Chernossolo Argilúvico (N/M), a qual possui uma área de 25.327ha no mapa ampliado. Esta área, no mapa semidetalhado, é ocupada, principalmente, por Argissolos Vermelhos e Vermelhos - Amarelos (3.579ha), Cambissolos Háplicos (13.610ha) e Neossolos Litólicos (2.986ha), entre outras classes menos expressivas em termos de área. Portanto, excluindo os Neossolos, com apenas $11,79 \%$ dos 25.327 ha, equivocadamente assim delimitados do mapa de reconhecimento ampliado, os 22.341ha restantes, apresentam alguma aptidão para uso agrícola. Assim, como no caso do município de SJP, a utilização das informações do mapa de reconhecimento de solos ampliado do RS (BRASIL, 1973) para o planejamento municipal de SPS, pode acarretar em falhas nos projetos a serem implantados, podendo promover problemas ao desenvolvimento do município.

Este trabalho comprova o fato de que em mapas de solo de pequena escala como o do Levantamento de Reconhecimento dos Solos do RS na escala de 1:750.000 (BRASIL, 1973), não é adequado representar os solos ocorrentes nas áreas mapeadas, por problema de escala. Por isto, o uso das informações destes mapas não é recomendado para planejamento de uso e manejo dos solos de municípios, bacias hidrográficas ou propriedades rurais. Para estes fins, mapas semidetalhados e, ou, detalhados, em escala de 1:50.000 ou maiores, necessitam ser produzidos. O trabalho também mostra que o procedimento de ampliar os mapas de escala pequena como 1:750.000 para 1:50.000 ou 1:20.000 é inadequado, porque os solos possíveis de serem representados nestas escalas, não foram separados nos mapas de escalas de 1:750.000.

É importante frisar que os mapas de solos produzidos ao nível de reconhecimento representam importantes inventários dos recursos de solos que ocorrem em grandes áreas e servem para efetuar estudos de zoneamento pedoclimáticos, seleção de áreas para efetuar projetos de colonização, seleção de trechos mais favoráveis à construção de rodovias e ferrovias, localização de estações experimentais em nível regional, entre outras, conforme especificado em EMBRAPA(1995).

\section{CONCLUSÕES}

Verificaram-se grandes diferenças na ocorrência e distribuição das classes de solos delineadas em mapas de pequena escala (1:750.000) em relação a mapas de solos de grande escala (1:20.000 a 1:50.000), como também na percentagem de área ocupada pelas classes delineadas nestes mapas de diferentes escalas. O procedimento de ampliar mapas de pequena escala não permite identificar e delinear solos que não foram representados nos mesmos. Os levantamentos de reconhecimento de solos representam uma etapa importante no inventário do recurso solo de um estado. Porém, completada esta etapa, cabe direcionar os investimentos para mapas em escalas maiores, detalhados ou semidetalhados $(\geq 1: 50.000)$, essenciais para fins de planejamento de 
solos em nível de propriedades rurais, microbacias hidrográficas ou municípios.

\section{REFERÊNCIAS BIBLIOGRÁFICAS}

BRASIL, Ministério da Agricultura. Levantamento de reconhecimento dos solos do estado do Rio Grande do Sul. Recife : convênio MA/DPP - SA/ DRNR, 1973. 431p. (Boletim Técnico, 30).

EASTMAN, J.R. Idrisi 32 release 2: reference guide. Worcester : Clark Univesity, 2001. 15p. 1 CD.

EMBRAPA. Centro Nacional de Pesquisa em Solos. Procedimentos Normativos de Levantamentos Pedológicos. Brasília : Embrapa, 1995. 116p.

EMBRAPA. Centro Nacional de Pesquisa em Solos. Sistema Brasileiro de Classificação de solos. Brasília : Embrapa, 1999. 412p.

DENT, D.; YOUNG, A. Soil survey and land evaluation. London : Allen \& Unwin, 1981. 278p.
IBGE. Levantamento de recursos naturais do projeto RadamBrasil. Folha SH.22. Porto Alegre e parte das folhas SH. 21 Uruguaiana e Si. 22 Lagoa Mirim. Rio de Janeiro, 1986. 796p.

KLAMT, E.; DALMOLIN, R.S.D.; CABRAL, D.R. Solos do Município de São João do Polêsine. Santa Maria : Depto. de Solos/CCR/UFSM, 1997. 93p.

KLAMT, E.; FloreS, C.A.; CABRAL, D.R. Solos do Município de São Pedro do Sul. Santa Maria : Depto. de Solos/CCR/UFSM, 2001. 96p.

RAMALHO FILHO, A.; BEEK, K.J. Sistema de avaliação da aptidão agrícola das terras. 3.ed. Rio de Janeiro : EMBRAPA-CNPS, 1995. 65p.

SALEHI, M.H.; EGHBAL, M.K.; KHADEMI, H. Comparison of soil variability in a detailed and a reconnaissance soil map in central Iran. Geoderma, v.111, p.45-56, 2003.

STRECK, E.V. et al. Solos do Rio Grande do Sul. Porto Alegre : Emater/RS - UFRGS, 2002. 126p. 